\title{
iCelebrate Teaching and Learning: Sharing the iPad Experience
}

\section{Cathy Cavanaugh ${ }^{1}$, Jace Hargis, Stephen Munns and Tayeb Kamali ${ }^{2}$}

Abstract: The purpose of this overview article is to describe the initial development of iPad pedagogy by analyzing the pre-implementation pedagogical practices shared at a national professional development event for and by iPad faculty. The context, event, data, analysis and results are described, along with implications for the following stages of program implementation. Specifically, the study asks; To what extent do faculty shared practices display technological pedagogical content knowledge (TPCK) prior to implementation of the iPad program in classrooms? The answers to this question will inform further professional development and form a baseline for understanding the path of faculty development in adopting, designing, and applying mobile education practices in a large-scale mobile learning initiative, because TPCK is foundational to effective teaching in a mobile learning environment. The analysis of sessions shows that the initial level of integration of the mobile education innovations into the curriculum was limited, and may require more time and practice in order to move from an emphasis on tools to an emphasis on content. The Technological Knowledge reflected in the abstracts was similarly emerging in that it emphasized "turnkey" apps and media, rather than more complex collaborative and production tools. Pedagogical Knowledge as represented by attributes of meaningful learning was strong in active learning, but included fewer of the more complex and interactive attributes, indicating that faculty members are beginning their adoption of this innovation with familiar and simpler strategies. Regarding their technological pedagogical knowledge, faculty members have progressed beyond entry level and have room to grow toward infusion and transformation.

Keywords: Faculty development, mobile learning, pedagogy

\section{Introduction.}

In April 2012, the federal higher education system of the United Arab Emirates (UAE) embarked on the path to national adoption of the Apple iPad as the educational computing platform. The core objective of the adoption was improved learning and degree completion among students in academic programs in support of national development goals. From the National Higher Education development document, the goals are to:

- "Achieve individualized student learning consistent with "Post PC Era" trends;

- Introduce challenge-based learning or other progressive classroom pedagogy;

- Increased student participation and motivation;

- Enhance opportunities for cross-institutional collaboration between faculty members;

- Increase faculty collaboration through cross-institutional repositories of learning objects; and

- Facilitate the migration to e-books."

\footnotetext{
${ }^{1}$ Abu Dhabi Women's College, PO Box 41012, Abu Dhabi, United Arab Emirates, ccavanaugh@hct.ac.ae

${ }^{2}$ Higher Colleges of Technology, PO Box 5464, Abu Dhabi, United Arab Emirates
} 
The UAE has three institutions encompassing 20 campuses serving 41,000 students in its federal higher education system: UAE University provides a research-intensive experience; Zayed University, is a comprehensive liberal arts environment; and the Higher Colleges of Technology (HCT), offers professional programs.

The federal iPad initiative, which will change how students are taught and learn, was the vision of His Excellency Sheikh Nahayan Mabarak Al Nahayan, Minister for Higher Education and Scientific Research, and Chancellor of the three institutions. H.E. Sheikh Nahayan issued the institutions with an innovative challenge and a vision to integrate the concept of mobile learning into the daily lives of those institutions' students and faculty. The institutions were mandated to implement the initiative by the start of the new academic year in September 2012. Dr Tayeb Kamali, HCT Vice Chancellor, was charged with leading the pan-institutional initiative and headed the project's steering committee. This program builds on his history of entrepreneurship and e-learning initiatives, such as integrated wireless campus infrastructures, online learning and knowledge-management programs.

The timeline for the adoption and implementation was ambitious and was undertaken in partnership between federal higher education and Apple leaders. The adoption and planning stage comprised the nine-week period before the summer break in the education calendar when the staff, curriculum, and campuses geared up for the program's launch upon the start of the 2012-2013 year scheduled for 9 September. For faculty, this 9-week period focused on preparing to meet the pedagogical goals of the UAE's iPad program: engaged, student-centered, progressive teaching. The purpose of this overview article is to describe the initial development of iPad pedagogy by analyzing the pre-implementation pedagogical practices shared at a national professional development event for and by iPad faculty. The context, event, data, analysis and results are described, along with implications for the following stages of program implementation. Specifically, the study asks:

To what extent do the faculty's shared practices display technological pedagogical content knowledge (TPCK) (Mishra \& Koehler, 2006) prior to implementation of the iPad program in classrooms?

The answers to this question will inform further professional development and form a baseline for understanding the path of faculty development in adopting, designing, and applying mobile education practices in a large-scale mobile learning initiative, because TPK is foundational to effective teaching in a mobile learning environment.

In addition to the national development and planning activities, structured iPad training sessions and informal faculty sharing activities occurred at every institution. These activities addressed topics such as drivers and factors that are influencing the Post-Laptop Era; teaching and learning with the iPad; demonstrations of recommended apps for Foundation Math and English courses; and demonstrations of eBook creation using iBooks Author.

Guiding the faculty development efforts in iPad pedagogy were the Apple stages of technology adoption: Entry, Adoption, Adaptation, Infusion and Transformation. These stages are described as developmental, with greater change required and greater impact expected at higher levels (Apple Computer, 1995). For the new pedagogy to be appropriate and active in UAE courses, faculty need to Adopt and Adapt the technology as a teaching and learning tool in their practice. These changes depend on a sustained faculty development and access to devices, appropriate apps, and evaluation rubrics. For the iPads to be infused fully into higher education, support is needed for accompanying new paradigms of learning. Ultimately, the iPad and student-centered tool-based teaching and learning can transform the higher education student 
learning experience, and post-graduate results in the UAE. Such transformation is about the people. Transforming a national higher education culture requires intense focus in order to capitalize and build on the richness of ideas and people to realize our vision of optimizing meaningful, relevant learning for all students. Apple's stages of technology adoption form an element of framework for the study's question.

A heuristic teaching approach aligns well with the iPad implementation because it is flexible, personalized, and student-centered. Heuristic serves to indicate or point out; stimulating interest as a means of furthering investigation. Heuristic in Greek means 'I find out'. In heuristic teaching, students drive learning as discoverers. The iPad can be their vehicle as they explore and propose responses to real-world course-contextualized challenges posed by faculty. In challenge-based learning (CBL), a difficult challenge is scaffolded by tasks that build upon each other. The challenge can be gamified so that students progress level by level as they accomplish each task. A proposed support for CBL is a project planning app that maps course objectives to tasks and suggested resources, formative assessments, collaboration tools, media creation tools, authentic portfolios, and other elements of the learning environment. In addition, a CBL design template is recommended based on Design Thinking practices to guide faculty in their course development. A heuristic teaching approach instantiated in design projects and challenge-based learning is a student-centered approach that is expected to be meaningful to students. Characteristics of the meaningful learning environment form an element of the framework for the study's question.

Attributes of a meaningful learning environment were selected to represent pedagogical knowledge because these attributes align well with the 2011-2013 UAE Government Strategy for a "first-rate education system" (UAE Cabinet, 2011) and with the Higher Colleges of Technology Graduate Learning Outcomes, as shown in Table 1.

Table 1. Alignment of meaningful learning with UAE education strategies and outcomes.

\begin{tabular}{lll}
\hline $\begin{array}{l}\text { Meaningful learning } \\
\text { environments }\end{array}$ & UAE first-rate education strategy & $\begin{array}{l}\text { HCT graduate learning } \\
\text { outcomes }\end{array}$ \\
\hline Active & Self-education & Critical thinking \\
Authentic & $\begin{array}{l}\text { Work values, Matching education } \\
\text { with labor market requirements }\end{array}$ & $\begin{array}{l}\text { Information literacy, } \\
\text { Technological literacy } \\
\text { Communication, Global }\end{array}$ \\
Collaborative & Sport and competitions & $\begin{array}{l}\text { Comareness and citizenship } \\
\text { awning }\end{array}$ \\
Constructive & Readiness for higher education & Creative thinking \\
Goal-directed & Empirically-focused curriculum and & $\begin{array}{l}\text { Self-management and } \\
\text { independent learning }\end{array}$ \\
\hline
\end{tabular}

The complete framework for examining the faculty initial status with regard to iPad pedagogy is shown in Table 2.

\section{Literature Review.}

Increasingly, students, employers, and community leaders expect colleges and universities to adopt technology tools in education. Education organizations respond in a variety of ways to change in technology, from avoiding it to embracing it. Adoption of technology-supported education innovations by an educator is an adaptation to changes in the conditions in which 
students live, the conditions in which they will be expected to succeed beyond their education, and our knowledge about the nature of learning (Liu, Cavanaugh, \& Ritzhaupt, in press). Mobile technology integration is an organizational shift and a form of innovation that involves openness and responsiveness to new learning environments. The quality of organizational change is a factor of an education organization's culture (Whetten \& Cameron, 1994) and capacity for change facilitation (McDermott \& Dell, 2001). In organizations where change facilitation is especially effective, leaders take explicit steps to enable the innovation to occur, playing an important role in the adoption of technology-supported education in learning environments (Hew \& Brush, 2007). Such leadership influences the educational technology integration (Fox \& Henri, 2005; Hew \& Brush, 2007). An important step for leaders of educational technology change is professional development at the outset and continuing through the implementation of the innovation. Such organizational learning is facilitated by leaders who encourage creative ideas, nurture promising practices in their initial stages, provide resources needed to develop new ideas, encourage experimentation with new approaches, and use reflection to analyze new processes (Yukl, 2009).

Table 2. Criteria for analysis of faculty pedagogy.

\begin{tabular}{|c|c|c|}
\hline TPCK Construct & Review Criteria & Supporting Literature \\
\hline Content & Academic Content Area & \\
\hline $\begin{array}{l}\text { Technological } \\
\text { (TK) }\end{array}$ & $\begin{array}{l}\text { Software and Digital } \\
\text { Resources }\end{array}$ & $\begin{array}{l}\text { Hogarty, Lang \& Kromrey, } \\
\text { 2003; Lowther, Ross \& } \\
\text { Morrison, } 2001\end{array}$ \\
\hline Pedagogical Knowledge (PK) & $\begin{array}{l}\text { Attributes of Meaningful } \\
\text { Learning } \\
\text { Environments }\end{array}$ & $\begin{array}{l}\text { Jonassen, Howland, Moore \& } \\
\text { Marra, } 2003\end{array}$ \\
\hline $\begin{array}{l}\text { Technological Pedagogical } \\
\text { Knowledge (TPK) }\end{array}$ & $\begin{array}{l}\text { Level of Integration (ACOT } \\
\text { Continuum) }\end{array}$ & $\begin{array}{l}\text { Sanholtz, Ringstaff \& Dwyer, } \\
\text { (1997) }\end{array}$ \\
\hline
\end{tabular}

Past mobile education research has shown that teaching practices change with the infusion of technology resources, professional development, and support (Dawson, Cavanaugh, \& Ritzhaupt, 2008). Mobile teaching practices fall within a continuum of technology integration strategies. In order for new approaches, tools, resources, and environments to transform pedagogy in ways that facilitate student-centered, engaged, meaningful learning, they must be adopted, adapted, and infused in practice by education institutions. The connection between professional development and effective use of classroom technology has been documented in large-scale studies (Ritzhaupt, Dawson, \& Cavanaugh, 2012):

- A teacher's level of education and experience teaching with technology positively and significantly influence his/her use of technology;

- Teacher use of technology strongly and positively explains classroom technology integration; and

- How a teacher integrates technology explains how frequently students use technology in a school setting.

Team-oriented approaches to the professional development such as professional learning communities support changes in teaching practices including the use of technology (Seels, Campbell, \& Talsma, 2003). The UAE's national approach to professional development for the 
iPad program has been to bring campus-based teams of faculty and support staff together in faceto-face and virtual collaborative learning communities for activities that promoted mobile technology integration and developing technological-pedagogical skills.

In the UAE program, the iPad was adopted as the platform because it has been shown to facilitate the desired pedagogy and learning environments. Apple mobile devices have been on college campuses for almost a decade. The first mobile device, the iPod has been shown to engage students in active, inquiry-based learning, shown to be a critical element of sustained learning (Hargis, et al, 2008). One of the main advantages of using the iPad in the context of teaching and learning is its ease of use and relatively low background knowledge for operation. Yee and Hargis (2012) have shown that people display a wide range of assumptions about how intuitive technology has to be before it becomes a useful investment of time and mental energy. Teachers being able to quickly move past the technology and onto the pedagogy are an essential game-changer unseen in prior emerging technology. Mayberry and Hargis (2012) have determined that using a device such as the iPod Touch, faculty members can embed useful low threshold learning and engage in meaningful scholarship of teaching and learning. Effective meaningful teaching with mobile technology is underpinned by developing intersecting knowledge of teaching, the technology, and the content (TPCK). The following sections examine the level of TPCK detected in the teaching practices shared by faculty who facilitated sessions in the UAE's iCelebrate Teaching and Learning event during the planning stage of the iPad program.

\section{III. iCelebrate Teaching and Learning.}

The UAE's iPad program for higher education was steered by a committee of educators and leaders who guided the broad organizational adoption of mobile education innovations through a comprehensive program of professional development activities designed to scaffold technological pedagogical growth. One of these activities was a faculty members' sharing event that occurred 8 weeks into the program planning stages prior to the start of classes. This event, iCelebrate Teaching and Learning, was held at a central location in the country.

One of the largest higher education campuses in the UAE is the Abu Dhabi Women's College (ADWC), which employed educational technologists and educational researchers who had experience in leading large-scale education innovation initiatives. Soon after the iPad program was announced, the leaders of ADWC conceived of the national iCelebrate Teaching and Learning event as a culmination of the academic year and a venue for sharing what faculty have learned and planned for their teaching in the following fall, based on the understanding that peer interaction and collegial sharing can contribute in significant ways to learning new innovations and strategies (Nicolle \& Lou, 2008).

The call for proposals for iCelebrate can be found at www.adwc.hct.ac.ae/icelebrate.

In order to further the instructional developments that have taken place over the last two months, this event will provide an occasion for teachers to share their experiences and ideas about using the iPad for teaching and learning. The day will offer concurrent sessions running from 9 am until $3 \mathrm{pm}$ with lunch provided. There will also be an Idea Zone where participants can reflect, brainstorm, and continue conversations started during the sessions. You are requested to submit abstracts for 15 minute or 45 minute interactive conversations centered on the integration of the iPad into teaching and learning. Facilitators are encouraged to 
explore effective teaching approaches in ways that engage participants and give them many concrete ideas, which they can implement in their courses in September. Sessions should be created with the purpose of sharing ideas and experiences surrounding teaching and learning with the iPad. They may be for exploratory discussion and need not be fully formed. Please submit your bio of not more than 300 words, and short abstract(s) of not more than 500 words.

The event attracted 68 presenters who facilitated 51 sessions for 450 participants from all federal higher education institutions across the country. The section below describes the nature of the sessions, which represent faculty learning in the first month of the iPad program preparation period. The data for this study are the abstracts of the faculty sharing sessions, because the abstracts represent a broad sample of pedagogical practice.

\section{Descriptive Analysis of Session Abstracts.}

Each presenter submitted an abstract session description, which served as the data set for the following analysis. The analysis entailed review of each abstract by a rater with experience in educational technology and one-to-one computing research. The analysis was conducted in four phases in order to characterize the sessions and to construct a baseline of faculty iPad pedagogy just prior to classroom implementation. The reviewer evaluated the lesson for evidence of technological pedagogical content knowledge (Mishra \& Koehler, 2006). Data were exported into an Excel spreadsheet. We conducted descriptive statistical analysis, including frequencies. We calculated the number of content topics, the number of each level of technology integration, and the percentage of specific technologies used in the sessions.

Phases of abstract analysis:

1. Content

2. Technological Knowledge (TK)

3. Pedagogical Knowledge (PK)

4. Technological Pedagogical Knowledge (TPK)

\section{A. Content.}

Each abstract was open-coded to identify the academic Content area application of the session. The codes were categorized into logical categories reflective of the college curriculum. The list below shows the percentage of the sessions that were placed in each category.

Content categories:

$16 \%$ English

$12 \%$ Math

$58 \%$ General

$2 \%$ ICT

6\% Faculty development

$8 \%$ Instructional design 
Faculty members were speaking to a broad and mixed audience of colleagues, which was reflected in the session topics. The majority of sessions had a general, cross-discipline application, while some focused specifically on Mathematic or English, those being the predominant teaching areas of participants in the iPad program. A few sessions addressed instructional design principles, faculty development approaches, and the ICT area.

\section{B. Technological Knowledge (TK).}

The broad realm of Technological Knowledge was represented by the types of apps and other digital resources used in the sessions (Hogarty, Lang, \& Kromrey, 2003; Lowther \& Ross, 2001). Each abstract was open-coded to identify the predominant technological emphasis of the session. The codes were categorized into logical categories. The list below shows the percentage of the sessions that were placed in each category.

Technology focus categories:

$80 \%$ Apps

$10 \%$ Media

$10 \%$ Web resources

$2 \%$ Collaboration, communication

6\% Operating System

4\% Productivity

$2 \%$ Games

The vast majority of sessions focused on specific apps, while a small number addressed media and other web resources. Few sessions addressed the mobile operating system, general productivity tools, communication and collaboration, or games. Given the early stage of educational technology use for many faculty members and the very early point in the iPad program, this pragmatic approach is understandable. Using technology as a tool that aligns to specific course objectives is aligns with early stages of technology adoption, which are addressed in the third phase of this analysis. Using technology for higher cognitive level transactions like participation in social environments and games aligns with more advanced stages of adoption that may be seen more frequently as this program continues (Sandholtz, Ringstaff, \& Dwyer, 1997).

\section{Pedagogical Knowledge (PK).}

PK was documented in the abstracts according to the attributes of meaningful learning environments - active, constructive, authentic and cooperative (Jonassen et. al., 2003). Each abstract was rated using a rubric with indicators of the meaningful learning environment.

The list below shows the percentage of the sessions that were placed in each category.

$92 \%$ Active

$36 \%$ Authentic

$38 \%$ Constructive

14\% Collaborative

14\% Goal-directed 
Because the ubiquitous iPad lends itself to active and engaged learning (Dale \& Pymm, 2009; Martinez, 2011), most sessions showed characteristics of active learning, such as hands-on mathematics, note taking, media authoring, and using augmented reality. Between 35 and 38 sessions referred to authentic or constructive approaches such as creating professional presentations, participating in communities, developing portfolios, and designing e-books. Fourteen percent of sessions made reference to collaborative or goal-directed approaches like practice to reach specific language levels, using games to develop specific skills, and networking with social media. Higher education in the UAE stresses authentic, workforce-oriented course experiences and student-constructed projects, making those approaches more ingrained in teaching practice. However, collaborative learning approaches have been rarer in the entry-level courses targeted by the iPad program because of concerns about online communication and because of the traditional nature of secondary education.

\section{Technological Pedagogical Knowledge.}

We represented TPK using the five-level continuum for technology integration initially developed during the Apple Classrooms of Tomorrow (ACOT) study (Sandholtz, Ringstaff, \& Dwyer, 1997): entry, adoption, adaptation, infusion and transformation. These levels represent a continuum of technology integration from entry level, which involves teachers using technology to present to students to adoption and adaptation levels which involve students using single technology tool (adoption) or choice of technology tools (adaptation) to create a digital product to infusion and transformation where the technology becomes an integral part of supporting student autonomy and learning (infusion) or becomes an essential tool in carrying out a lesson that would not be possible without its use (transformation). As shown below, more than $90 \%$ of the sessions were found on the first three levels of the ACOT continuum: entry, adoption, and adaptation

The list below shows the percentage of the sessions that were placed in each category.

$2 \%$ Entry

$52 \%$ Adoption

$38 \%$ Adaptation

$4 \%$ Infusion

$2 \%$ Transformation

The Bridge/Foundations faculty members have an average six years' experience in the UAE and teaching experience is required to begin as a faculty member here., Thus they are likely to have at least an entry level of technology experience. However, teaching with the iPad and its resources was very new to most, who received their iPads a few days or weeks prior to the iCelebrate event. The iPads were not distributed to students at that time, so very few had taught with an iPad. Therefore, it was laudable that only one of the sessions was limited to the Entry level of technology integration and 54\% reached the Adoption level. Examples of adoption were identification of tools for mathematics and language skills, as well as tools for digitizing teaching materials.

Over one-third of sessions reached Adaptation level, judging by the sessions focused on new formats and sources for teaching materials such as news feeds, and tools that add capability to current teaching practice such as collaborative note taking and other forms of sharing and 
feedback. Admirably, three sessions reached Infusion or Transformation levels, in which technology was used to significantly gamify a program and replace static media with studentcreated and social media. Future events and other classroom data collection are likely to reveal development of teaching practices at higher levels as the devices and resources are infused throughout each campus (Cavanaugh, Dawson, \& Ritzhaupt, 2011; Ritzhaupt, Dawson, \& Cavanaugh, 2012).

\section{Discussion and Conclusions.}

Given the short timeline between the decision to adopt iPads for the federal institutions in April 2012 and the iCelebrate event on 20 June, the willingness of faculty to commit to implementation was essential. At ADWC for instance, faculty were supported by a fast-track training program that combined input from professionals in educational technology with a heuristic approach in which they were encouraged to 'discover and share' learning opportunities in small and large-group sessions.

The data from iCelebrate suggests that faculty responded positively, with 56 presenters, 51 from HCT, including 33 from the host College, 4 from ZU and 1 from UAEU. In addition to the presenters, there were 284 attendees. As noted earlier, $80 \%$ of the technology focus was on apps. While the timeline and perhaps the level of faculty expertise made this a predictable outcome, faculty preparedness to engage with the iPad initiative remained an unknown prior to the iCelebrate event. The TPCK analysis of sessions facilitated by the faculty who had the confidence to submit an abstract shows that the initial level of integration of the mobile education innovations into the curriculum was limited, and may require more time and practice in order to move from an emphasis on tools to an emphasis on content. The Technological Knowledge reflected in the abstracts was similarly emerging in that it emphasized "turnkey" apps and media, rather than more complex collaborative and production tools. Pedagogical Knowledge as represented by attributes of meaningful learning was strong in active learning, but included fewer of the more complex and interactive attributes, indicating that faculty members are beginning their adoption of this innovation with familiar and simpler strategies. Regarding their technological pedagogical knowledge, faculty members have progressed beyond entry level and have room to grow toward infusion and transformation.

The effective integration of iPads into the federal institutions' educational programs, coupled with a sustainable development plan, requires not only recognition of faculty engagement as indicated by iCelebrate, but also a response. One task of managers and policymakers will be to ensure that faculty engagement, professional development and the quality of course delivery are consistent and monitored not only in regard to the three institutions, but more significantly the twenty campuses that fall within their purview. One method for measuring the consistency of faculty engagement and the quality of teaching and learning would be to adopt the Substitution, Augmentation, Modification and Redefinition (SAMR) model (Puentedura, 2010), which would enable the categorization of teaching and learning at individual campuses and therefore record emergent trends at a local level.

The SAMR model reflects the transformative potential of teaching and learning, which is in turn a primary aim of iPadagogy. Strategically applying the SAMR model at a local level would provide a categorization measurement indicating the extent to which teaching and learning tasks are transformative, for example, and so map 'iPadagogy in practice'. It would also assist policy-makers in arriving at informed decisions in the ongoing process of improved education in 
areas such as research, professional development, shared practice, comparative analysis, creativity and quality of educational delivery.

It seems reasonable to ask what 'iPadagogy in practice' will look like. Although currently in its nascent and quite possibly most dynamic stage of development, iPadagogy envisions the creation of eLearning Objects (eLO) that support Challenge-Based Learning (CBL) and InquiryBased Learning (IBL). This is aligned to a heuristic approach to teaching and learning, which is highly student-centered and asserts trial and error or rational decision making as underlying the cognitive action of discovery and problem solving. The educational affordances of the iPad and the predilection of iPadagogy for heuristics suggest that while there is a great deal of creative scope in the development of eLOs, iPadagogy is also based upon well-founded educational practice. In order to sustain iPadagogy, the UAE's higher education federal institutions will need to fully commit to its heuristic philosophy, not only in Foundations/Bridge programs but all programs and not only thorough eLOs, but also through the development of Challenge-Based eAssessment Objects (eAO). Successful implementation of iPadagogy will help ensure that the next iCelebrate event will focus less on Apps than eLOs and eAOs that generate ChallengeBased Learning opportunities through games and productivity-based activities.

While iPadagogy builds from the foundation of general educational technology and learning with mobile technology in particular, many differences distinguish today's learners, tools, and learning environments from those of previous decades. One difference is in the pace of development, introduction, and adoption of new learning resources. These conditions require amplification of the educators' and leaders' mindsets that value innovation (Reimers-Hild, 2009) and recognize that education must change because of technologies (Lankshear \& Knobel, 2006). The iCelebrate event is a step in building communities based on these mindsets, and is a recommended approach for other large-scale, diverse mobile education initiatives.

\section{References}

Apple Computer, Inc. (1995). Changing the conversation about teaching, learning, \& technology: A report on 10 years of ACOT Research. Cupertino, CA: Apple Computer, Inc.

Cavanaugh, C., Dawson, K., \& Ritzhaupt, A. D. (2011). An evaluation of the conditions, processes and consequences of laptop computing in K-12 classrooms. Journal of Educational Computing Research, 45(3), 359-378.

http://baywood.metapress.com/link.asp?id=g01m85m746u4r15q

Dale, C., \& Pymm, J. (January, 2009). Podagogy. Active Learning in Higher Education, 10(1), 84-96. http://alh.sagepub.com/content/10/1/84.abstract?etoc

Dawson, K., Cavanaugh, C., \& Ritzhaupt, A. (2008). Florida's Leveraging Laptops initiative and its impact on teaching practices. Journal of Research on Technology in Education. 41(2), 143159.

Fox, R., \& Henri, J. (2005). Understanding teacher mindsets: IT and change in Hong Kong schools. Educational Technology \& Society, 8(2), 161-169. 
Hargis, J., Jensen, S., Kohn, C., Normand, M., \& Schooler, D. (2008). Providing faculty iPods to explore innovative teaching and learning. Journal of Effective Teaching, 8 (2), 19-29. http://uncw.edu/cte/ET/articles/Vol8_2/Hargis.htm

Hew, K.F., \& Brush, T. (2007). Integrating technology in k-12 teaching and learning: current knowledge gaps and recommendations for future research. Education Technology Research \& Development, 55, 223-252.

Hogarty, K.Y., Lang, T.R., \& Kromrey, J.D. (2003). Another look at technology use in classrooms: The development and validation of an instrument to measure teachers' perceptions. Educational and Psychological Measurement, 63(1), 139-162.

Jonassen, D., Howland J., Moore, J., \& Marra, R. (2003). Learning to Solve Problems with Technology: A Constructivist Perspective (2nd ed.). Upper Saddle River, NJ: Merrill Prentice Hall.

Lankshear, C., \& Knobel, M. (2006). New Literacies: Everyday Practices and Classroom Learning. Maidenhead: Open University Press.

Liu, F., Cavanaugh, C., \& Ritzhaupt, A.D. (In press). Leaders of school technology innovation: A confirmatory factor analysis of the Change Facilitator Style Questionnaire (CFSQ). Journal of Educational Administration.

Lowther, D.L., Ross, S.M., \& Morrison, G.M. (2003). When each one has one: The influences on teaching strategies and student achievement of using laptops in the classroom. Educational Technology Research and Development, 51(3), 23-44.

Martinez, J.E. (2011). A Performatory Approach to Teaching, Learning, and Technology. Rotterdam: Sense. https://www.sensepublishers.com/files/9789460916663PR.pdf

Mayberry, J., Hargis, J., Meler, M., Boles, L., Dugas, A., O’Neill, D., \& Rivera, A. (2012). New faculty explore teaching and learning in higher education using an iTouch. Journal of Active Learning in Higher Education, 13 (3), 45-61.

McDermott, R., \& O’Dell, C. (2001). Overcoming cultural barriers to sharing knowledge. Journal of Knowledge Management, 5(1) 76-85.

Mishra, P., \& Koehler, M. (2006). Technological pedagogical content knowledge: A framework for teacher knowledge. The Teachers College Record, 108(6), 1017-1054.

Nicolle, P., \& Lou, Y. (January 2008). Technology adoption into teaching and learning by mainstream university faculty: A mixed methodology study revealing the how, when, why, and why not. Journal of Educational Computing Research, 39 (3), 235-265. http://baywood.metapress.com/link.asp?id=3q8284r2227xq521 
Project Tomorrow National Findings. (April 2011). The new 3 E's of education: enabled, engaged, empowered - how today's students are leveraging emerging technologies for learning. http://www.tomorrow.org/speakup/pdfs/SU10_3EofEducation(Students).pdf

Puentedura, R. (2010). SAMR and TPCK: intro to advanced practice. http:/hippasus.com/resources/sweden2010/SAMR TPCK IntroToAdvancedPractice.pdf (accessed May 2012)

Reimers-Hild, C. I., \& King, J.W. (2009). Six questions for entrepreneurial leadership and innovation in distance education. Online Journal of Distance Learning Administration, 12(4), http://www.westga.edu/ distance/ojdla/winter124/reimers-hild124.html

Ritzhaupt, A.D., Dawson, K., \& Cavanaugh, C. (2012). An investigation of factors influencing student use of technology in K-12 classrooms using path analysis. Journal of Educational Computing Research, 46(3). http://baywood.metapress.com/link.asp?id=972t6qv475615511

Sandholtz, J., Ringstaff, C., \& Dwyer, D.C. (1997). Teaching with Technology: Creating Student Centered Classrooms. New York, NY: Teachers College Press, Columbia University. http://store.tcpress.com/0807735868.shtml

Seels, B., Campbell, S., \& Talsma, V. (2003). Supporting excellence in technology through communities of learners. Educational Technology Research and Development, 51(1), 91-104. http://www.springerlink.com/content/v442443417q1q098/

Whetten, D.A., \& Cameron, K.S. (1994). Organizational effectiveness: Old models and new constructs. In J. Greenberg (Ed.), Organizational Behavior: The State of the Science. Hillsdale, NJ: Lawrence Erlbaum Associates.

Yee, K., \& Hargis, J. (February 2012). When I should (Not) use technology. Journal of the National University of Singapore Teaching Academy (JNUSTA), 1(2), 65-69. http://www.nus.edu.sg/teachingacademy/jnusta/v2n1/v2n1p65_YeeKevin.pdf

Yukl, G. (2009). Leading organizational learning: Reflections on theory and research. The Leadership Quarterly, 20, 49-53. 